\title{
Transfer of Training: An Interpretive Review
}

\author{
Stephen M. Cormier \\ Training and Simulation Technical Area \\ Training Research Laboratory
}
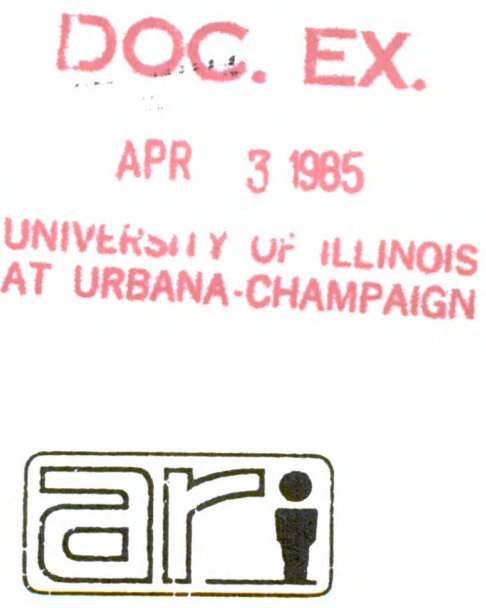

U. S. Army

Researct Institute for the Behavioral and Social Sciences

January 1984

Afproved for Jubic release; cistricu ion uritimited. 